\title{
Study on the strength of a fishing boat made from plastic recycles
}

Noverdo Saputra, Budhi Martana*, Noorohmah, Fahrudin, Reda Rizal

Faculty of Engineering, Universitas Pembangunan Nasional Veteran Jakarta, Indonesia

\begin{abstract}
Ship's strength is a very significant factor in ship design. In this research, a study of the strength of ships made of recycled plastic material has been carried out. The ship has been designed according to the needs of the load weight, passengers, propulsion system, fishing equipment and the weight of the material itself. Then the load is distributed into the design, where the profile shape and plate thickness used are assumed to be temporary. The strength of the boat analysed, and the minimum plate thickness required in the design is $10 \mathrm{~mm}$ with maximum strain The recycle plastic used is type 2 (HDPE).
\end{abstract}

Keywords: Boat's Plastic Recycle, Boat's Strength, HDPE Plastic Recycle

\section{Introduction}

According to data from the Ministry of Environment and Forestry in 2016, Indonesia annually produces around 9.85 billion pieces of plastic bags. Approximately 90 thousand modern outlets generate waste. That is, the plastic waste it produces takes about 20 to 500 years to completely decompose. And if left unchecked, it will disrupt the balance of nature. One way that can be done to reduce plastic waste is to recycle it so that it can be used as an item with other functions. With the development of technology, more and more innovations are found, such as the use of plastic waste as a mixture of various handicrafts and household appliances that use plastic-based materials [1][2][8].

The shipping industry has experienced many technological developments and many innovations in the selection of materials used for the manufacture of ship hulls. As one of the innovations used is the use of type 2 plastic material (HDPE), which, Turkey first used type 2 plastic material (HDPE) as a boat-building material. Where, type 2 plastic material (HDPE) aims to replace shipbuilding materials using fiberglass reinforced plastic (FRP), fiberglass reinforced plastic (FRP) material is considered more environmentally unfriendly than the use of type 2 plastic (HDPE) which is better and safer for humans. environment.

Because with the advancement of technology in the shipping world, the author tries to make a new breakthrough by making materials from plastic waste, using type 2 plastic waste (HDPE) which if left unchecked will damage the environment, it is hoped that this material has the advantage of being durable, resistant to corrosion for approximately 50 years to decompose, has small cracking power so that it can reduce damage, and has high flexibility so it is very suitable in case of bad weather at sea, and can be recycled again .

\section{Literature Review}

According to data from the Ministry of Environment and Forestry in 2016, Indonesia annually produces around 9.85 billion pieces of plastic bags. Approximately 90 thousand modern outlets generate waste. That is, the plastic waste it produces takes about 20 to 500 years to completely decompose. And if left unchecked, it will disrupt the balance of nature. One way that can be done to reduce plastic waste is to recycle it so that it can be used as an item with other functions. With the development of technology, more and more innovations are found, such as the use of plastic waste as a mixture of various handicrafts and household appliances that use plastic-based materials [8].

The shipping industry has experienced many technological developments and many innovations in the selection of materials used for the manufacture of ship hulls. As one of the innovations used is the use of type 2 plastic material (HDPE), which, Turkey first used type 2 plastic material (HDPE) as a boat-building material. Where, type 2 plastic material (HDPE) aims to replace shipbuilding materials using fiberglass reinforced plastic (FRP), fiberglass reinforced plastic (FRP) material is considered more environmentally unfriendly than the use of type 2 plastic (HDPE) which is better and safer for humans. environment.

Because with the advancement of technology in the shipping world, the author tries to make a new

\footnotetext{
* Corresponding author : budhi.martana@upnvj.ac.id
} 
breakthrough by making materials from plastic waste, using type 2 plastic waste (HDPE) which if left unchecked will damage the environment, it is hoped that this material has the advantage of being durable, resistant to corrosion for approximately 50 years to decompose, has small cracking power so that it can reduce damage, and has high flexibility so it is very suitable in case of bad weather at sea, and can be recycled again .

\subsection{Plastic}

Plastics are polymers consisting of molecules called monomers which are commonly known as comonomer, if they meet different types of monomers, they are called copolymers. There are types of natural polymers that we are familiar with such as: cellulose, protein, natural rubber etc. However, natural polymers only survived in the 19th century and beyond, polymers experienced a fairly rapid development until for the first times polymers from nitrocellulose were distributed to the public until now used in household appliances etc [2][6]. The types of plastics can be seen. in below figure.

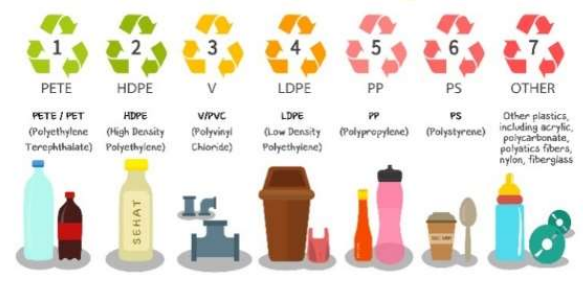

Fig. 1 Type of Plastic

Type 2 plastic (HDPE) is a type of plastic that has the ability to prevent chemical reactions between the plastic packaging and the packaged food or beverage. HDPE also has the characteristics of being stronger, harder, opaque, and resistant to high temperatures. Because HDPE is made from petroleum, to make $1 \mathrm{~kg}$ of HDPE requires around $1.75 \mathrm{~kg}$ of petroleum as the raw material for its manufacture. We can find many types of HDPE plastic in our daily lives, such as: shampoo packaging, plastic bags, milk packaging, plastic rolls and others, the HDPE manufacturing process is made with a catalyst process. Because, type 2 plastic (HDPE) is a type of plastic that can be recycled, therefore, the processing process is by first sorting it from other types of plastic. After that, the process of crushing type 2 plastic (HDPE) in the recycling plant. Then, the smelting process is the last process of a product can be seen in below figure [2][4].

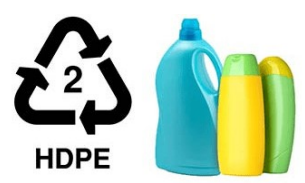

Fig. 2 HDPE

\subsection{HDPE Boat}

Some countries have applied HDPE as material for small boat, like Turkey, Germany and other. The application has success by use virgin HDPE variant like sheet HDPE, powder or granule. And this method also has conducted in Indonesia for 5-6 six years ago. There are some advantage use HDPE as main material for small boat; not corrosive, good in impact, small resistance (low roughness resistance), easy to make and assembly, low maintenance and $100 \%$ recycle [9][5][3].

\section{Methodology Research}

Noverdo et all [9] has tried to applicate recycle HDPE into non class boat. The methodology will apply in this research as follow chart

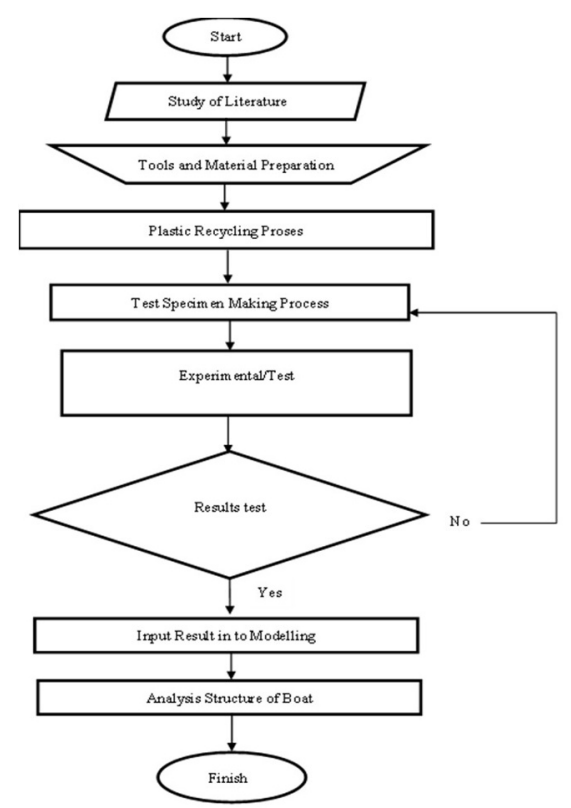

Fig. 3. Reserach Flow diagram

\section{Research Experiment}

Some of the tests carried out are as follows:

\subsection{Tensile Test}

The test aims to determine the strength of the material based on the resistance of a material to the tensile load of a test material. Tensile testing is carried out by adding the load slowly, which then increases in length which is proportional to the working force. Materials that cannot withstand relatively low stress are brittle materials.

\subsection{Bending Test}

This test can also be referred to as testing the flexibility of the material to a centre of gravity attached to two supports. Tests are carried out to determine whether the material is deformed or not by two opposing forces at the same time 


\subsection{Impact Test}

This test is carried out to determine the brittleness or ductility of a material to be tested by sudden loading with static test equipment.

\subsection{Design of Test Specimen}

The specimen design used is in accordance with the ASTM standard. For tensile test using ASTM D368, bending test using ASTM D790 3, and impact test using ASTM D256.

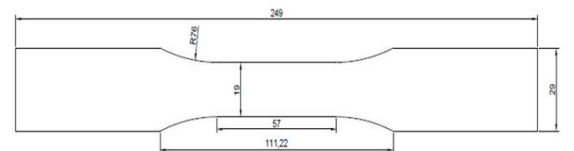

Fig. 4. Tensile Test Specimen Design

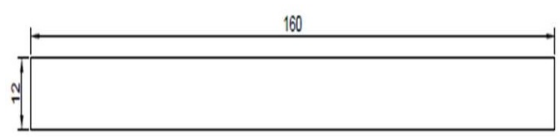

Fig.5. Bending Test Specimen Design

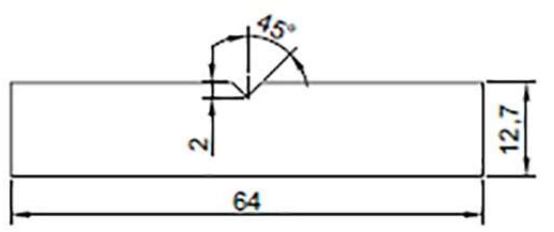

Fig.6. Impact Test Specimen Design

\subsection{Experimental Tools}

The following are the tools used and have international standards and have been calibrated

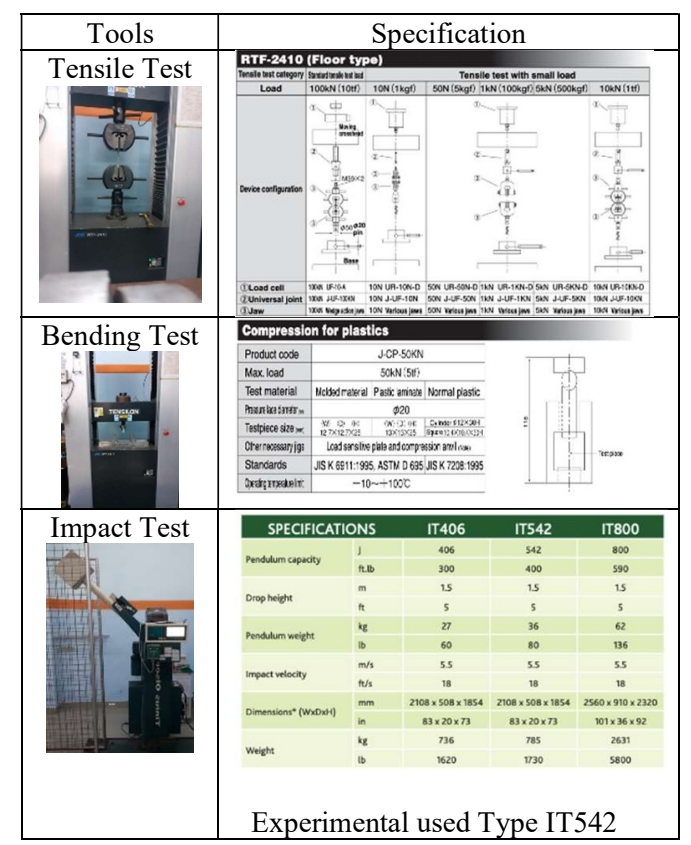

Fig.7. Experimental Tools

\section{Experiment Result}

\subsection{Tensile Test}

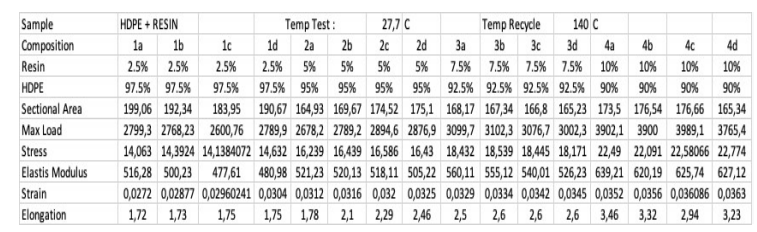

Fig. 8. Tensile Test of Recycle HDPE

Tensile test of type 2 recycles plastic (HDPE) and resin with a ratio of $97.5 \%: 2.5 \%$ resulted in different tensile strengths of 4 test specimens (1a-1d). The larger result is 14,632 and minimum is 14,063 . Tensile test of type 2 plastic (HDPE) and resin with a ratio of $95 \%: 5 \%$ resulted in different tensile strengths of 4 test specimens (2a-2d). The larger result is 16,586 and minimum is 16,239. Tensile test of type 2 plastic (HDPE) and resin with a ratio of $92.5 \%: 7.5 \%$ resulted in different tensile strengths of 4 test specimens (3a-3d). The larger result is 18,171 and minimum is 18,539 . Tensile test of type 2 plastic (HDPE) and resin with a ratio of $90 \%$ : $10 \%$ resulted in different tensile strengths of 4 test specimens (4a-4d). The larger result is 22,091 and minimum is 22,774 . As per above data, it was obtained that the larger stress was found in the specimen with a ratio of $90 \%$ : $10 \%$ for type 2 plastic (HDPE) with the addition of resin. Detail stress and strain every specimen test, please see below graphic.

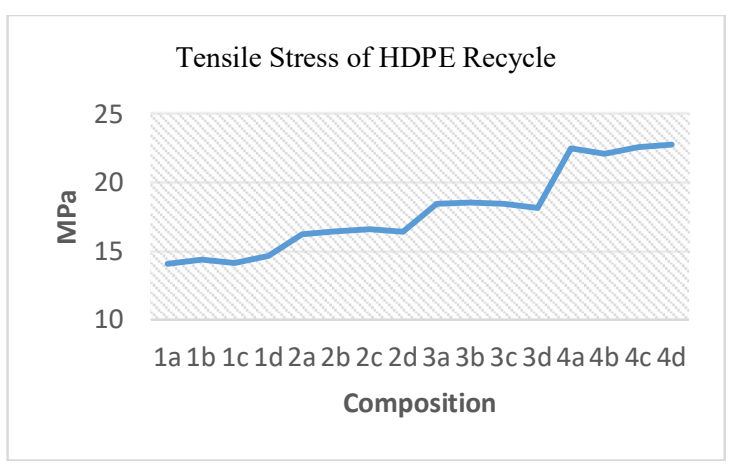

Fig.9. Tensile Stress of HDPE Recycle

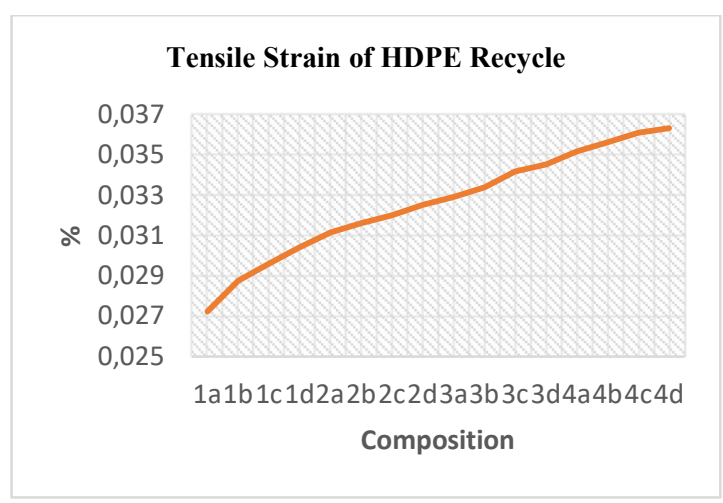

Fig. 10. Tensile Strain of HDPE Recycle 


\subsection{Bending Test}

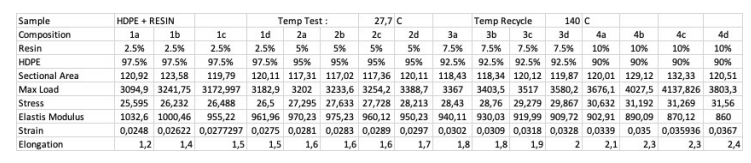

Fig.11. Bending Test of HDPE Recycle

Bending test of type 2 recycle plastic (HDPE) and resin with a ratio of $97.5 \%: 2.5 \%$ resulted in different bending strengths of 4 test specimens (1a-1d). The larger result is 25,595 and minimum is 26,5 . Bending test of type 2 plastic (HDPE) and resin with a ratio of 95\%: $5 \%$ resulted in different bending strengths of 4 test specimens (2a-2d). The larger result is 27,295 and minimum is 28,213 . Bending test of type 2 plastic (HDPE) and resin with a ratio of $92.5 \%: 7.5 \%$ resulted in different bending strengths of 4 test specimens (3a$3 d)$. The larger result is 28,43 and minimum is 29,867 . Bending test of type 2 plastic (HDPE) and resin with a ratio of $90 \%$ : $10 \%$ resulted in different bending strengths of 4 test specimens (4a-4d). The larger result is 31,56 and minimum is 30,362 . After described above, it was obtained that the larger stress was found in the specimen with a ratio of $90 \%: 10 \%$ for type 2 plastic (HDPE) with the addition of resin. Detail stress and strain every specimen test, please see below graphic.

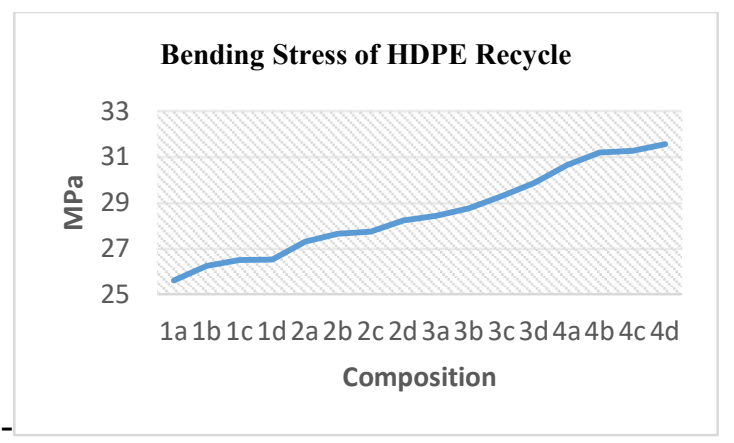

Fig.12. Bending Stress of HDPE Recycle

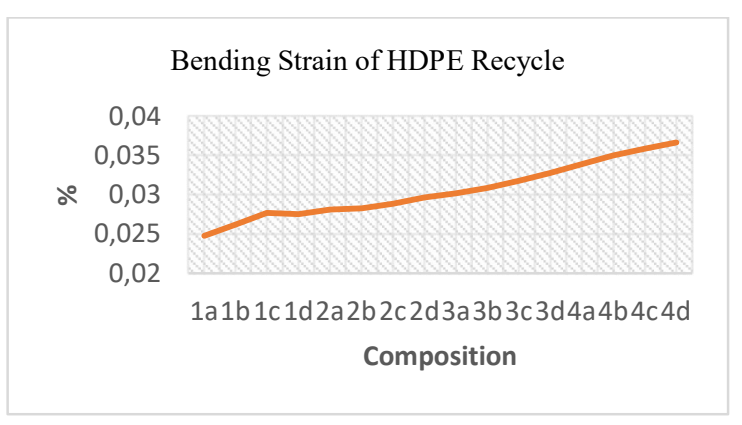

Fig.13. Bending Strain of HDPE Recycle

\subsection{Impact Test}

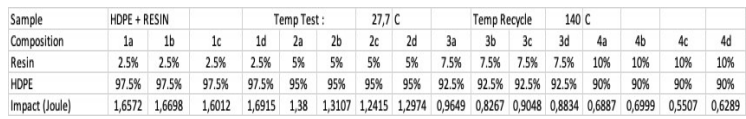

Fig.14. Impact Test of HDPE Recycle
Impact test of type 2 recycle plastic (HDPE) and resin with a ratio of $97.5 \%: 2.5 \%$ resulted in different impact strengths of 4 test specimens (1a-1d). The larger result is 1,6012 and minimum is 1,6915. Impact test of type 2 plastic (HDPE) and resin with a ratio of $95 \%: 5 \%$ resulted in different impact strengths of 4 test specimens (2a-2d). The larger result is 1,2415 and minimum is 1,38. Impact test of type 2 plastic (HDPE) and resin with a ratio of $92.5 \%$ : $7.5 \%$ resulted in different impact strengths of 4 test specimens (3a-3d). The larger result is 0,9649 and minimum is 0,8267 . Impact test of type 2 plastic (HDPE) and resin with a ratio of $90 \%$ : $10 \%$ resulted in different impact strengths of 4 test specimens (4a-4d). The larger result is 1,6915 and minimum is 1,6012. After described above, it was obtained that the larger stress was found in the specimen with a ratio of 97.5\%: $2.5 \%$ for type 2 plastic (HDPE) with the addition of resin. Detail stress every specimen test, please see below graphic.

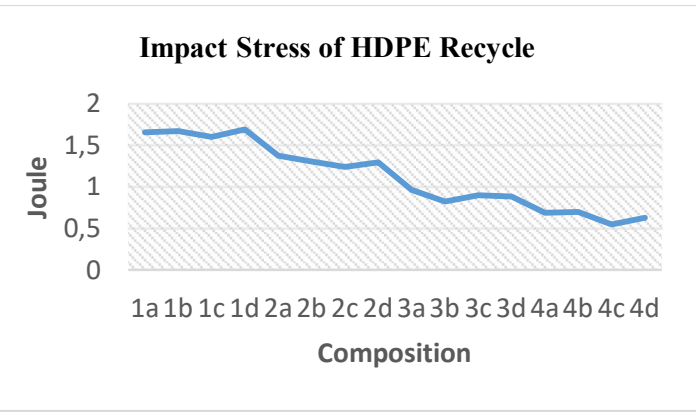

Fig.15. Impact Stress of HDPE Recycle

\subsection{Strength of Fishing Boat}

Modelling of fishing boat has been carried out used sample of Maxsurf model include frame, stiffener and web frames.

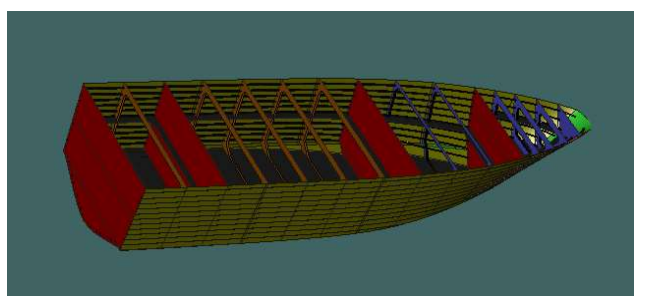

Fig.16. Modelling hull and structure of fishing boat

This boat has designed for 3 GT of fishing vessel with hull thickness, web frame and stiffener approximate 10 $\mathrm{mm}$. After input all recycle material data into the software, strain of hull can be as per below figure

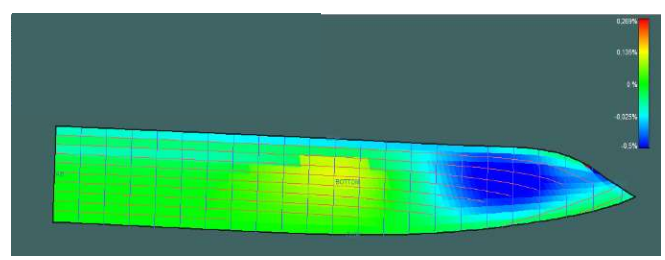

Fig.17 Strain with 3 GT Payload 
Maximum strain has occurred in this model is 0,027

\section{Conclutions}

1. HDPE Plastic waste has recycled use mechanical method (with oven) and without pressure become HDPE recycle sheet with $10 \mathrm{~mm}$ thickness.

2. That recycle HDPE has been test as per international standard for plastic, tensile test use ASTM D368, bending test use ASTM D790, and impact test use ASTM D256.

3. Maximum tensile stress has occurred is $22,774 \mathrm{MPa}$ and Maximum strain is 0,0363 for composition $90 \%$ HDPE recycle and $10 \%$ of Resin (yukalac 157 ), it is proven that the addition of resin increases the tensile strength.

4. Maximum bending stress has occurred is 31,56 $\mathrm{MPa}$ and maximum strain is 0,0367 for composition 90\% HDPE recycle and $10 \%$ of Resin (yukalac $157)$, it is proven that the addition of resin increases the bending strength.

5. Maximum impact stress has occurred is 1,6915 $\mathrm{MPa}$ for composition 97.5\% HDPE recycle and $2.5 \%$ of Resin (yukalac 157), it is proven that the addition of resin decreases the impact strength.

6. Additional of resin increase tensile as bending strength, while decrease of impact strength

7. Boat has designed for 3GT fishing boat

8. Maximum strain for $3 \mathrm{GT}$ fishing boat for $10 \mathrm{~mm}$ thickness is 0,027

9. Comparing with figure 8 , figure 11 , figure 14 with margin $20 \%$, Design $3 \mathrm{GT}$ boat with minimum $10 \mathrm{~mm}$ thickness is recommended to use HDPE recycle with composition 90\% HDPE recycle and $10 \%$ Resin (Yukalac 157). For designed fender and forepeak of boat use is recommended use pure recycle HDPE (100\% of HDPE Recycle).

10. Future development is recommended to process HDPE plastic waste with pressure.

\section{References}

[1]. J R. Jambeck, C W Roland, R Siegler, M Perryman, A Anthony, N Ramani,L Kara 2015 Plastic waste inputs from land into the ocean (Dd: Sciencemag.org).

[2]. A. Papanikolaou 2015 Optimization of the Preliminary Design and Cost Evaluation of Fishing Vessels (ed: Ship Technology Research).

[3]. Jamal, Wasis AD, Strength Evaluation of Pompong Structure Made from High Density Polyethylene Plastics as Basic Materials, The 4th International Seminar on Fisheries and Marine Science, December 3, (2015).

[4]. P. W. M. Institute 2016, An Introduction to Plastic Recycling (ed: pwmi.or.jp).

[5]. Siswandi B, Wasis D A, High Density Polyethylene (HDPE) Vessel of Pompong as a Fishing Vessel for Bengkalis Fisherman, The 2nd International Seminar on Science and
Technology August 2nd 2016, Postgraduate Program Institut Teknologi Sepuluh Nopember, Surabaya, Indonesia

[6]. M. E. Grigore 2017 Methods of Recycling, Properties and Applications of Recycled Thermoplastik Polymers (ed: www.mdpi.com/journal/recycling).

[7]. W. d'Ambrières 2019 Plastics recycling worldwide: current overview and desirable changes(ed:http://journals.openedition.org/facts reports/5102).

[8]. Ministry of Finance Republik Indonesia. (2019). Bumi Dalam Kantong Plastik. Media Keuangan, XIV(144), 1-30

[9]. Noverdo S, Iswadi N, Bambang S, Reda R, 2021 Study of Utilization Plastic Waste as Basic Material for Boat Manufacturing Using Ecogreen Design Concept, IOP Conference Series: Materials Science and Engineering, Vol. 1125, Workshop on Environmental Science, Society, and Technology (WESTECH 2020) 16-17 October 2020, Makassar, Indonesia 